\title{
Initiation of Meiotic Homologous Recombination: Flexibility, Impact of Histone Modifications, and Chromatin Remodeling
}

\author{
Lóránt Székvölgyi ${ }^{1}$, Kunihiro Ohta ${ }^{2}$, and Alain Nicolas ${ }^{3}$ \\ ${ }^{1}$ Department of Biophysics and Cell Biology, Faculty of Medicine, University of Debrecen, \\ 4032 Debrecen, Hungary \\ ${ }^{2}$ Department of Life Sciences, The University of Tokyo, 113-8654 Tokyo, Japan \\ ${ }^{3}$ Institut Curie Centre de Recherche, UMR3244 CNRS, Université Pierre et Marie Curie, \\ 75248 Paris CEDEX 05, France \\ Correspondence: lorantsz@med.unideb.hu; alain.nicolas@curie.fr
}

\begin{abstract}
Meiotic recombination is initiated by the formation of DNA double-strand breaks (DSBs) catalyzed by the evolutionary conserved Spo11 protein and accessory factors. DSBs are nonrandomly distributed along the chromosomes displaying a significant ( $\sim 400$-fold) variation of frequencies, which ultimately establishes local and long-range "hot" and "cold" domains for recombination initiation. This remarkable patterning is set up within the chromatin context, involving multiple layers of biochemical activity. Predisposed chromatin accessibility, but also a range of transcription factors, chromatin remodelers, and histone modifiers likely promote local recruitment of DSB proteins, as well as mobilization, sliding, and eviction of nucleosomes before and after the occurrence of meiotic DSBs. Here, we assess our understanding of meiotic DSB formation and methods to change its patterning. We also synthesize current heterogeneous knowledge on how histone modifications and chromatin remodeling may impact this decisive step in meiotic recombination.
\end{abstract}

Sexual reproduction depends on halving the genome content of germ line cells and faithful chromosome transmission during meiosis to yield viable gametes. Meiosis comprises one round of DNA replication and two successive rounds of chromosome segregation, allowing the reduction of a diploid genome to produce haploid gametes (Fig. 1A).

Central to meiosis is the process of recombination between the paternal and maternal chromosomes (interhomolog recombination), which is crucial to enhance the genetic diversity of the gametes, but also for providing physical connections among homologs. These connections (i.e., chiasmata) ensure proper alignment of homologous chromosome pairs on the spindle, promoting proper reductional segregation following the regulated release of the sister chromatid cohesion among the duplicated chromosomal arms (Watanabe 2012). Defective meiotic recombination is a source of de novo germline mutations, abnormal genome content in gametes (the source of Down's syndrome), and infertility. Not surprisingly, cells have developed a variety of mechanisms and tight controls to ensure sufficient and well-dis-

Editors: Stephen Kowalczykowski, Neil Hunter, and Wolf-Dietrich Heyer

Additional Perspectives on DNA Recombination available at www.cshperspectives.org

Copyright (C) 2015 Cold Spring Harbor Laboratory Press; all rights reserved; doi: 10.1101/cshperspect.a016527

Cite this article as Cold Spring Harb Perspect Biol 2015;7:a016527 
L. Székvölgyi et al.

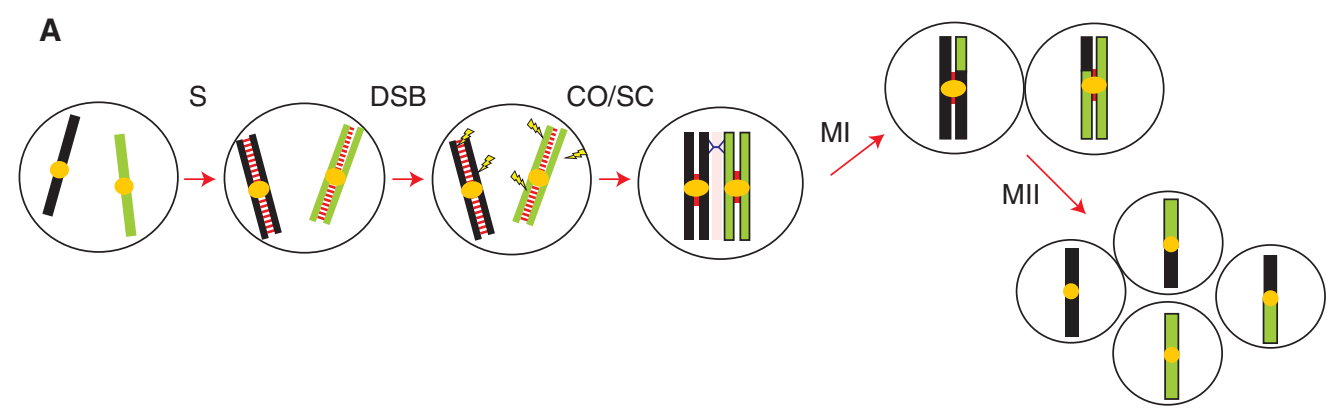

B

1: Initiation
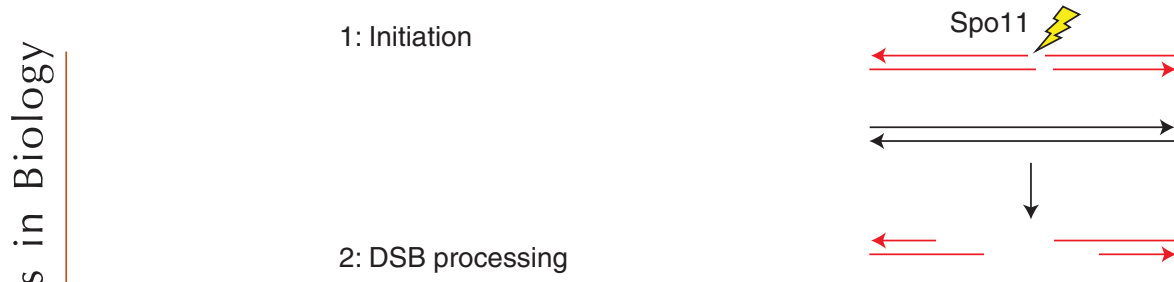

3: DSB repair
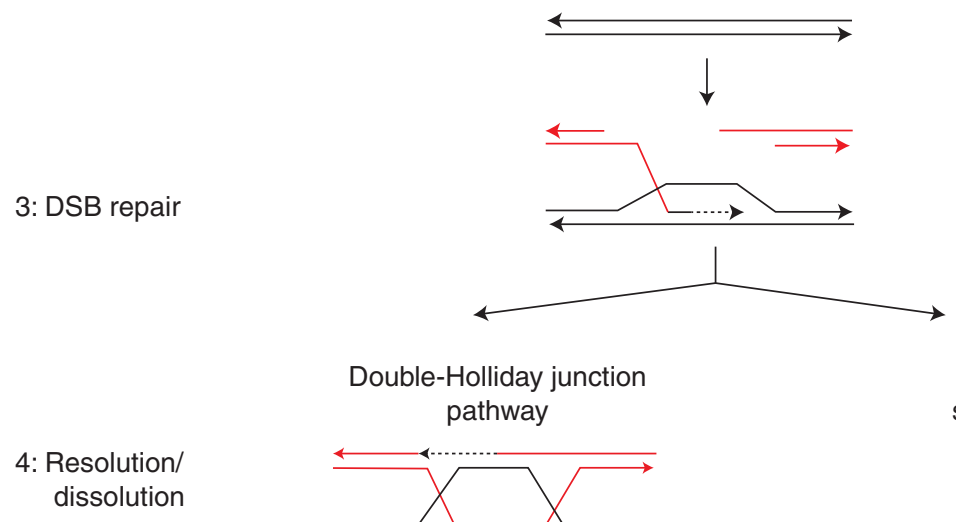

Double-Holliday junction pathway

Synthetic-dependent strand-annealing pathway dissolution
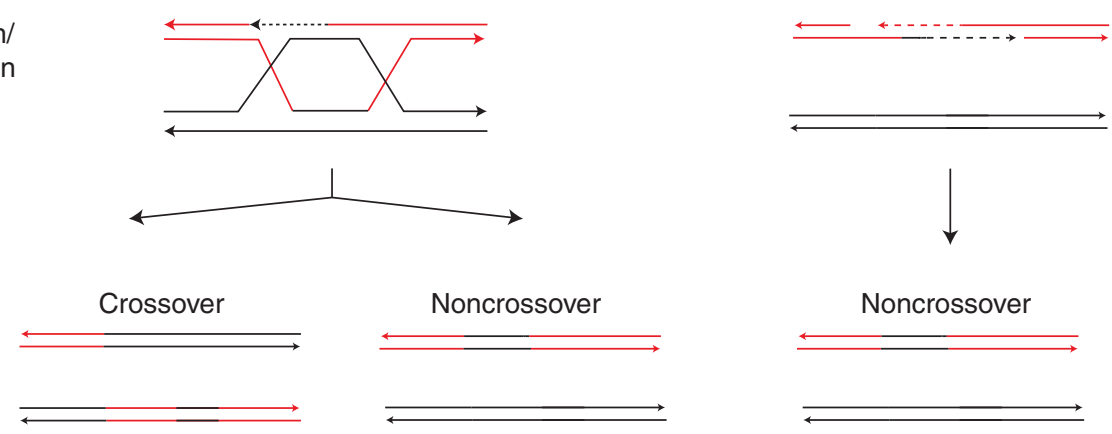

Noncrossover

Figure 1. The stages and mechanisms of meiosis. $(A)$ Diploid yeast cells initiate meiosis on nutrient depletion and in the presence of a nonfermentable carbon source. In mammals, the process is started by endocrine/ paracrine/juxtacrine stimuli from the surrounding cell and tissue environment. Relevant molecular stages are indicated: S, meiotic replication; DSB, double-strand breaks; CO, crossover; SC, synaptonemal complex; MI, and MII (first and second meiotic divisions, respectively). Colors: parental homologous chromosomes (green and black), sister chromatid cohesion (red), SC (pink). (B) The mechanism of meiotic recombination. Stage 1: Initiation. DSBs are introduced by the Spo 11 protein. Stage 2: DSB processing. Strand resection initiates to yield $3^{\prime}$ single-stranded DNA (ssDNA) overhangs. One of the $3^{\prime}$ ssDNA tails engages in strand invasion and a homology search of the homologous chromosome, resulting in single-end invasion (SEI) and D-loop intermediates. Stage 3: DSB repair. (Legend continues on following page.) 
tributed meiotic recombination events within their genomes.

At the DNA level, meiotic recombination can be divided in four successive stages (Fig. 1B): (1) initiation, which consists in the formation of programmed DNA DSBs; (2) DSB processing, which yields the recombinogenic single-strand tails; (3) homologous DSB repair, which involves the homologous recombination pathway and several meiosis-specific differentiation modulations, which facilitate interhomolog interactions; and (4) intermediate resolution and dissolution, which allow the formation of local (up to a few kb in length) noncrossover (NCO) gene conversion events and reciprocal crossovers (COs).

Recently, local and genome-wide studies of normal and mutant cells have uncovered a remarkable variability in the number and positioning of recombination events per chromosome and cell, which reveals an impressive level of flexibility (Székvölgyi and Nicolas 2010). In this review, we outline our understanding of the control of the initiation events, and how histone modifications and chromatin remodeling impact this initial step of meiotic recombination. The process of meiotic recombination and its relationship to change in chromosome structures and movements, allowing homolog alignment, pairing, and synapsis, is also reviewed in Zickler and Kleckner (2015) and Lam and Keeney (2015).

\section{MEIOTIC DSBs AND RECOMBINATION EVENTS ARE NONRANDOMLY DISTRIBUTED}

In all organisms, meiotic recombination is initiated by the formation of a large number of programmed DNA DSBs per cell, which are repaired primarily via recombination between nonsister chromatids (recombination initiation occurs after replication) to generate $\mathrm{NCO}$ and $\mathrm{CO}$ recombinant products (Fig. 1B). These DSBs are catalyzed by the evolutionarily conserved Spo11 protein (Bergerat et al. 1997). Besides Spo11, a number of accessory proteins are required for DSB formation. In Saccharomyces cerevisiae, 10 DSB proteins are known and functional, but sometimes sequence-divergent orthologs are gradually being identified in other organisms, including mammals. Yeast two-hybrid and co-immunoprecipitation (IP) studies identified several multiprotein subcomplexes, which are successively recruited to the meiotic chromosomes before DSB formation in triggered (Arora et al. 2004; Panizza et al. 2011). The biochemical/structural functions of these DSB protein complexes remains poorly understood. They play a role to select the potential DSB regions along the chromosomes, and ultimately contribute to the recruitment of Spol1 and trigger cleavage.

Spo11 is orthologous to the topoVI family of topoisomerase discovered in archaea, and consistently introduces DSBs by coupled transesterification reactions to form covalent tyrosylDNA linkages at the $5^{\prime}$ termini of the broken DNA. Spo11 is then removed by endonucleolytic cleavage (Neale et al. 2005), liberating short Spo11-DNA oligonucleotide complexes and resected strands, which are further extended to generate recombinogenic $3^{\prime}$ single-stranded tails. Over the years, meiotic DSBs have been mapped and quantified in yeast genomic DNA using a variety of approaches, including Southern blot analysis of chromosomal fragments

Figure 1. (Continued) In the double-Holliday junction $(\mathrm{dHJ})$ pathway, the opposite DSB end is captured by annealing to the displaced strand of the D-loop, leading to the formation of a dHJ. In the synthesis-dependent strand-annealing (SDSA) pathway, repair of DSBs occurs without the formation of a dHJ. Stage 4: Resolution/ dissolution. In the $\mathrm{dHJ}$ pathway, after gap-filling DNA synthesis and nick ligation, the $\mathrm{dHJ}$ is cleaved on opposing single DNA strands, generating products that can be ligated. Depending on cleavage, the patterns $\mathrm{dHJ}$ resolution produces either $\mathrm{CO}$ recombinants (associated or not with gene conversion that results from $\mathrm{HJ}$ migration) or noncrossover (NCO) (gene conversions). In the SDSA pathway, the SEI intermediate undergoes DNA synthesis by extension of the invading DNA strand with D-loop dissolution, and the extended ssDNA ultimately reanneals to its original complementary ssDNA strand on the opposite side of the DSB. An intact duplex is then produced by gap-filling DNA synthesis and nick ligation, which gives rise to NCO recombinants. 
L. Székvölgyi et al.

or full-length chromosomes, PCR, chromatin immunoprecipitation (ChIP)-Chip, and ChIPseq analyses of enriched single-stranded DNA (ssDNA) (Buhler et al. 2007) and, most recently, via the purification and sequencing of Spo11associated oligos, providing exquisite resolution both in terms of mapping and quantification (Pan et al. 2011). The most amenable method to estimate the number of DSBs on a per-cell basis is to count the number of $\operatorname{Rad} 51 / \mathrm{Dmc1}$ immunostaining foci on spread meiotic nuclei (Bishop 1994). On a broad scale, these methods have provided consistent general conclusions. They show the evolutionary conservation of the mechanism of DSB formation and the essential role of interhomolog recombination for the production of viable, euploid meiotic products. Depending on the organism and mutant defect, a lack or reduction in DSB frequency can lead to arrest of meiotic progression and apoptosis, or progression and formation of inviable aneuploid gametes.

To address whether Spo11-catalyzed DSBs play a unique role in meiosis, the functionality of DSBs introduced by other nucleases and clastogenic agents has been examined. Interhomolog recombination was promoted by ionizing radiation (Bowring et al. 2006), indicating that Spo11-catalyzed DSBs are not unique in their ability to promote recombination during meiosis. Other studies used the expression of a heterologous endonuclease, such as HO (Kolodkin et al. 1986; Malkova et al. 2000), VDE (Hodgson et al. 2011), or I-SceI (Farah et al. 2009) in yeast, and the Mos1 transposase in Caenorhabditis elegans (Robert and Bessereau 2007). In all cases, interhomolog recombination was induced at the break sites. However, in several respects, the DSBs and recombinants induced by these systems are different than those resulting from Spo11. These site-specific DSBs are not bona fide Spo11 breaks because of (1) the uncontrolled timing of DSB induction, (2) the abnormal and dangerous cleavage of both sister chromatids, and (3) alteration in recombination efficiencies when assayed in the wild-type or Spo11-deficient strain background. This relates to the role of the Spo11 DSBs in the pairing of the homologs. The uniqueness of the Spo11 breaks might reside in its mode of cleavage that allows, like in other site-specific recombination processes, to intimately link break formation and processing, and also to avoid extensive DSB signaling associated with accidental DSBs (Borde et al. 2004). Furthermore, Spo11 break formation is intimately linked to the process of chromosome pairing that enforces interhomolog rather than intersister recombinational repair.

Extensive studies with $S$. cerevisiae (Baudat and Nicolas 1997; Gerton et al. 2000) and later with Schizosaccharomyces pombe (Cromie et al. 2007), Arabidopsis (Drouaud et al. 2013), mice (Smagulova et al. 2011), chimpanzee, and humans (Myers et al. 2010; Auton et al. 2012) showed that the distribution of meiotic DSBs is not random along chromosomes, explaining the longtime noted discrepancy between physical and genetic map distances. Nowadays, genetic distances are measured by high-throughput microarray or genome-wide sequencing analyses of meiotic progenies, starting from diploid heterozygous strains carrying thousands of single-nucleotide polymorphisms (SNPs). In a pioneer study in S. cerevisiae, Mancera et al. (2008) genotyped the four spores of several tetrads to reconstitute the meiotic recombination events per meiotic cell and, on average, found $\sim 90$ COs and 46 NCOs ( 66 after correction for undetected NCO) per meiosis. Consistently, these recombination events are located in correlation with the preferred sites of DSBs and, in a number, suggesting that a large majority of the DSBs (estimated to $\sim 150$ per meiosis) are repaired on the homologous chromosome. This is consistent with the single-site genetic and physical analysis of recombination intermediates at the most studied artificial HIS4::LEU2 hotspot, indicating that $\sim 80 \%$ of the meiotic DSBs are repaired using a nonsister chromatid rather than the sister chromatid as template (Lao et al. 2013). Genome-wide analysis of meiotic products in other organisms confirms that most DSBs are repaired by interhomolog recombination (Cole et al. 2010), but the large excess of DSBs relative to COs-identified directly or by counting the Rad51 and Dmc1 foci on meiotic prophase spreads over the final recombination products_ can be explained also if meiotic DSB 
repair frequently occurs among sister chromatids. This raises the key question of how and to what extent the interhomolog bias is implemented and, globally, to what extent the meiotic versus mitotic differentiation of DSB repair template choice is organism specific.

\section{MULTIPLE LAYERS OF CONTROL SHAPE THE DSB DISTRIBUTION: CLUSTERING, INTERFERENCE, AND REDISTRIBUTION}

If recombination-initiation sites were randomly distributed, DSBs would be equally likely to occur at any location along the chromosomes and would not influence one another (Fig. 2A). This is clearly not the case because (1) DSB frequencies vary greatly from site to site (at least 400 -fold in S. cerevisiae, S. pombe, and Arabidopsis) (Pan et al. 2011; Choi et al. 2013; Fowler et al. 2014). (2) DSB sites within a hotspot region are strongly localized. In S. cerevisiae, they are preferentially localized in intergenic promoter-containing intervals, but depleted from other regions (Baudat and Nicolas 1997). In S. pombe and mice, enhanced DSB formation occurs in various regions, but also alternate with regions showing low DSB activity. (3) Over longer distances, DSB-prone and -repressed regions are clustered in subchromosomal domains. The cold regions are found in interstitial coding regions, showing no specific pattern along the chromosomes, but DSB formation is always strongly suppressed in the telomere- and centromere-proximal regions, as well as within the recombinant DNA (rDNA). These quantitative and region-specific variations are indeed strong evidence for the nonrandom nature of the DSB distribution. The contribution of rare and, possibly, random (stochastic) DSBs is not excluded, but remains difficult to measure and map.

Figure 2A illustrates two hypothetical nonrandom modes of DSB distribution: (1) a uniform distribution, when every DSB falls as far from its neighbors as possible, and (2) clustered, when most DSBs are concentrated close together and large regions contain very few, if any, breaks. The observed DSB pattern in S. cerevisiae (Borde et al. 2009) illustrated for chromosome III falls between these two extremes; with some devia- tion, it falls closer to the clustered arrangement, indicating that the contribution of stochasticity might be significant. It is noteworthy that the current genome-wide DSB-mapping techniques (Spo11-oligo sequencing, Dmc1/Rpa/ ssDNA ChIP) obscure cell-to-cell variations in DSB formation (as do all mass-biochemical methods that investigate cell populations).

Other strong driver elements that shape the nonrandom distribution of DSBs have been documented in S. cerevisiae, but also remain poorly understood. These phenomena are referred to as "DSB interference" and appear to drive even spacing of DSBs and limit simultaneous breakage at allelic positions. First, the occurrence of DSBs reduces the probability of nearby DSBs to occur (Fig. 2B). This is a "cis-inhibition" process, in which strong DSB hotspots suppress the activity of nearby recombination-initiation sites on the same homolog (Xu and Kleckner 1995; Fan et al. 1997). This inhibitory effect of natural or targeted DSBs on adjacent hotspots is known to spread over significant distances along the chromosomes (up to $25-100 \mathrm{kbp}$ in S. cerevisiae) (Robine et al. 2007). The second interference phenomenon is that DSB formation on one homolog decreases DSB formation on the other homolog (trans-inhibition) at the cognate allelic position (Rocco et al. 1992; Zhang et al. 2011a). Whether these cis- and trans-regulatory events occur independently remains to be elucidated, but, importantly, the trans-modulation appears to be genetically controlled, involving the two signal transduction kinases Mecl (ATR) and Tel1 (ATM) acting as potential direct effectors of the trans-DSB interference (Zhang et al. 2011a; Blitzblau and Hochwagen 2013; Gray et al. 2013). The benefit to locally regulate DSB formation between the sister and nonsister chromatids is to prevent simultaneous DSB formation at the same place on more than one chromatid. This would generate poorly interacting broken molecules, perturb the efficiency of DSB repair, and, finally, facilitate mutagenic end-joining and out-of-register interactions between repeats, as well as genome rearrangements on ectopic interactions. Rare but naturally occurring events of this type may contribute to the arising of de novo germline mutations, a 
L. Székvölgyi et al.

A

Chromosome III coordinates (bp)

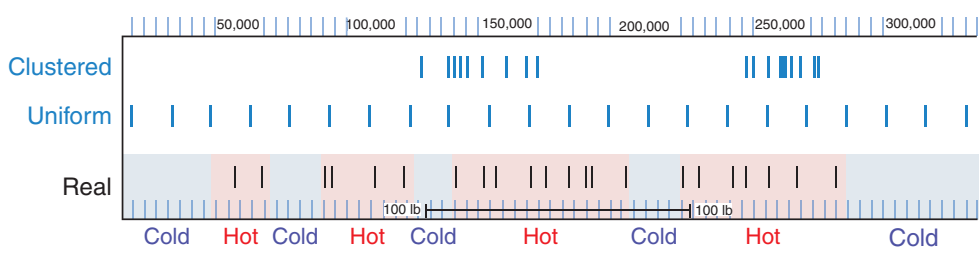

B

Early DSBs

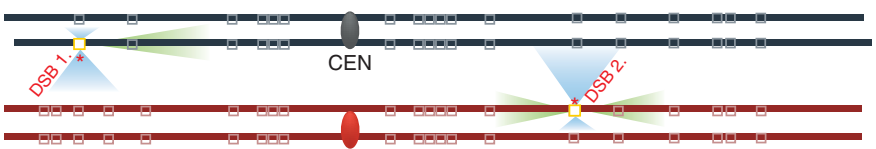

Late DSBs

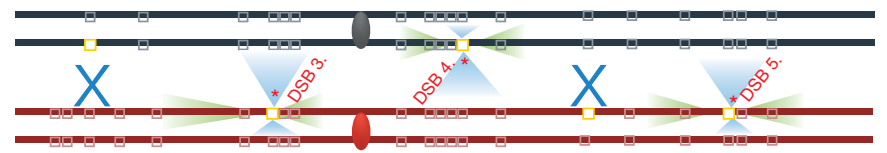

Evenly spaced interhomolog interactions

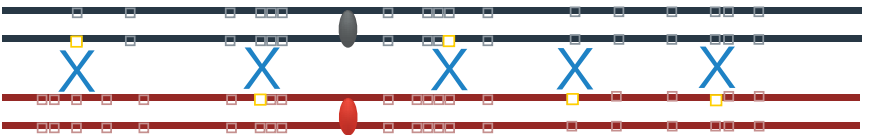

C

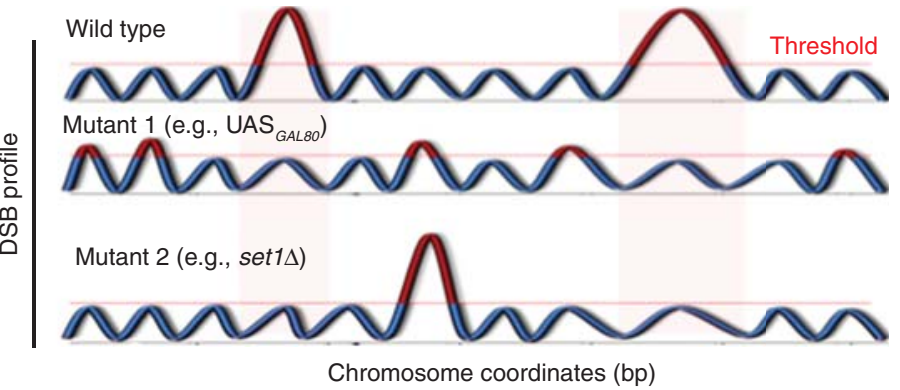

Figure 2. Spatial distribution of meiotic DNA double-strand breaks (DSBs) along the chromosomes. $(A)$ Hypothetical (blue) and real (black) DSB patterns, representing random and nonrandom distributions. Real DSBs (Borde et al. 2009) establish "cold" and "hot" domains, which alternate along the chromosomes length. (B) DSB interference establishes even spacing among interhomolog crossovers (COs). Interference nucleates at activated DSB sites (yellow rectangles) cleaved by Spo11 (red star) and spreads over significant distances along the sister/nonsister chromatids or homologous chromosome (trans-inhibition, blue triangles), or along the same sister chromatid (cis-inhibition, green triangles). DSBs form sequentially as meiosis progresses such that "late" DSBs fill in the gaps among "early" DSBs. A subset of DSBs matures into COs (blue crosses). (C) DSB redistribution can shuffle recombination-initiation events to reinforce the "obligatory" number of COs per chromosome. Mutant 1 can be, for example, an upstream activating sequence (UAS) ${ }_{\text {GAL80 }}$, mutant, in which the Gal4 binding site was inactivated to prevent DNA cleavage by the Gal4BD-Spol1 fusion protein. New DSBs readily appear nearby the UAS. Mutant 2 corresponds to, for instance, a set $1 \Delta$ mutant, in which the disappearance of "canonical" hotspots often results in the activation of latent hotspots. 
source of human diseases (Campbell and Eichler 2013). Also, cells with broken chromosomes may progress further into the meiotic prophase, and, unless they are arrested by the DNA damage checkpoint before MI, the chromosomes would segregate abnormally, yielding unbalanced genomes.

Another parameter that can result in DSB modulation is the unresolved question of the synchrony/asynchrony of DSB formation in individual meioses. Time-course experiments in synchronously sporulating yeast cell populations and mutant cells that accumulate unrepaired DSBs ( rad50S or sae2s) show that a majority of DSBs $(\sim 150$ in $S$. cerevisiae $)$ tend to occur within a 30 - to 60 -minute window, but the level of synchrony in these experiments remains insufficient to conclude whether the DSBs take place simultaneously or progressively in individual cells. This issue concomitantly raises the question of how the recruitment and biochemical cleavage activity of Spo11 are functionally and temporally regulated. Although Spo11's covalent attachment to the cleaved strand is a suicide mechanism preventing the turnover of the protein, a regulatory pathway must also exist to locally and/or globally terminate the window for DSB formation. How this happens is not understood. The capacity of certain pachytene arrested mutants (e.g., $n d t 80 \Delta$ ) to continue DSB formation (Xu and Kleckner 1995), and also the late persistence of Spol1 and other DSB proteins along the chromosomes after DSB formation (Arora et al. 2004; Cole et al. 2010; Gray et al.2013), are puzzling observations that call to further integrate the connection of DSB formation and repair with changes in chromosome structures and movements and explore the underlying signaling pathway(s) in connection to the meiotic cell-cycle progression.

Another important DSB control can be called "DSB compensation" to denote the homeostatic process that is able to redistribute DSBs along the chromosomes (Fig. 2C). When strong DSB sites become suppressed, locally or genome-wide, as a result of a mutation, a vast number of dormant DSB hotspots get activated to compensate for the loss of DSBs. Consequently, the original DSB distribution can be dra- matically remodeled. For instance, when the GAL4BD-Spo11 fusion protein (when the DNAbinding domain of the Gal4 transcription factor is fused with Spo11) (Pecina et al. 2002) targets DSBs near the $U A S_{G A L}$ DNA-binding motives, mutating the $U A S_{G A L}$ site at the GAL80 locus causes a severe drop of Gal4BD-Spo11targeted DSB levels (from $10 \%$ to $3 \%$ ) at the GAL80 promoter, but compensatory "weak" DSBs readily appear elsewhere, within the same intergenic region (Fig. 2C, middle track) (Robine et al. 2007). Also, null mutations of certain histone-modifying enzymes (e.g., $\operatorname{set} 1 \Delta$, $\operatorname{sir} 2 \Delta$, $\operatorname{Prdm} 9^{-I^{-}}$) significantly suppress the activity of canonical recombination hotspots, but a number of compensatory DSBs appear elsewhere (Fig. 2C, lower track) (Borde et al. 2009; Brick et al. 2012). For example, in $\operatorname{Prdm} 9^{-/-}$ knockout mice, lacking the sequence-targeted meiosis-specific histone-K4 methylase PRDM9, DSB sites are redirected to different genomic regions, which are flanked by PRDM9-independent H3K4me3 marks (Brick et al. 2012). In this way, "DSB compensation" can, at least in part, buffer the absence of natural ("frequent") recombination sites to assure the minimal level of DSBs required for homolog pairing and reinforce the "obligatory" COs per chromosome (i.e., $\geq 1 \mathrm{CO} /$ chromosome arm). It is noteworthy that canonical DSBs can be successfully compensated for in the absence of Set1, giving rise to viable spores (Acquaviva et al. 2013). On the contrary, Prdm9 mutants show severe defects in the progress of meiosis (Hayashi et al. 2005; Brick et al. 2012), indicating that these delocalized DSBs are, in some respects, different from naturally occurring DSBs. The differences between the physiological versus pathological outcomes for "relocalized" and "compensatory" DSBs need to be better understood, especially if they used to modify the natural landscape of meiotic recombination.

It is noteworthy that the total number of recombination events (overall recombination rate) and locations of COs (related to hotspot usage) are two distinct features, which are both determined genetically (Kong et al. 2014). For instance, single-nucleotide variants of PRDM9 affect both recombination rate and location. 
L. Székvölgyi et al.

Other genetic variants have been identified that alter the genetic map in humans: (1) CTCFL, the testis-specific paralog of CTCF, a Zn-finger protein organizing chromatin loops with cohesins (Sleutels et al. 2012), (2) the meiosis-specific cohesin RAD21L, which plays a role in the formation of meiotic chromosome axis and synapsis, (3) the SUMO ligase RNF212, ubiquitin ligase HEI10 (CCNB1IP1), and MutS homo$\log \mathrm{MSH} 4$, all related to members of the ZMM class of pro-CO factors identified in S. cerevisiae, although with different synapsis defects (Reynolds et al. 2013; Kong et al. 2014; Qiao et al. 2014). Strikingly, significant differences are seen among these genetic variants, as those having a large impact on recombination rates have no effect on hotspot usage. This implies that, in most cases, genetic variants affect the $\mathrm{CO}$ or NCO decision rather than directly touching on DSB formation. Accordingly, the yeast Zip3 protein preferentially localizes to DSB hotspots that tend to be repaired as COs (whereas Zip3 is depleted from NCO-biased hotspots) (Serrentino et al. 2013), pointing to the existence of distinct types of DSB sites with regard to $\mathrm{CO}$ and $\mathrm{NCO}$ formation.

\section{CHROMATIN REMODELING AND HISTONE MODIFICATIONS IMPACT MEIOTIC DSB FORMATION}

Overall, heritable polymorphisms can be a major source of quantitative genetic variation shaping the recombination landscape among individuals, but circumstantial and epigenetically inherited elements of the chromatin structure can also significantly contribute to the plasticity of DSB formation. DNA cleavage by Spo11 requires an accessible DNA template; hence, the energy barrier inherently exerted by nucleosomes and other chromatin-packaging proteins must be overcome. Because spontaneous rates of dissociation and sliding of nucleosome core particles vastly exceed biologically relevant timescales, diffusion-driven processes alone cannot account for the extensive reorganization seen at DSB sites in vivo. In mitotically dividing cells, the concerted action of histone-modifying activities and nucleosome remodelers stimu- lates nucleosome mobilization, end resection, and strand invasion at DSBs to finally restore the original chromatin structure. Although direct evidence is missing, the same processes are expected to hold for meiotic cells.

\section{Histone Modifications}

The chromatin-flanking DSB hotspots have a clear spatial organization of histone marks (Fig. 3A) such that H3K9ac falls closest to hotspots, followed by $\mathrm{H} 3 \mathrm{~K} 4 \mathrm{me} 3$ concentrated at the $+1,+2,+3$ nucleosomes, whereas H3K4me1/ me2, H3K36me3, H3K79me2, and H3R2me/ as are mainly present inside or at the $3^{\prime}$ ends of open reading frames (ORFs) (Zhang et al. 2011b). Histone H3K56 acetylation is a transient mark enriched on nucleosomes that show rapid turnover kinetics (Rufiange et al. 2007; Watanabe et al. 2013). These chemical labels can impact meiotic recombination (1) by affecting the structure and mobility of nucleosome core particles, and (2) by interacting with chromatinsignaling proteins that use histone modifications as docking sites. Mishaps in the proper writing, reading, and erasing of these biochemical tags can interfere with recombination, leading to the formation of pathological diseases, such as infertility or carcinogenesis (Schwartzentruber et al. 2012). Here, we mention a few remarkable examples from various model organisms that exemplify the association between histone modifications and meiotic DSBs. (1) In C. elegans, acetylation of histone $\mathrm{H} 2 \mathrm{~A}$ at lysine 5 (H2AK5ac) seems to play a crucial role in meiotic DSB and CO formation (Wagner et al. 2010). Deletion of the XND-1 gene (X nondisjunction factor 1) disrupts H2AK5 acetylation and induces a significant change in the meiotic DSB and CO landscape, with most COs occurring abnormally within the gene-rich regions of autosomes. (2) In fission yeast, H3K9ac is specifically enriched at recombination hotspots, but the "prototypical" DSB mark $\mathrm{H} 3 \mathrm{~K} 4 \mathrm{me} 3$ is less relevant (Yamada et al. 2013). Mutating the $\mathrm{H} 3 \mathrm{~K} 9$ residue mildly reduced levels of Rec12 binding (homologue of Spo11) and DSBs, indicating that $\mathrm{H} 3 \mathrm{~K} 9 \mathrm{ac}$ may facilitate recombination initiation by stabilizing the contact between 
Meiotic DSBs: Toward Chromatin Architecture
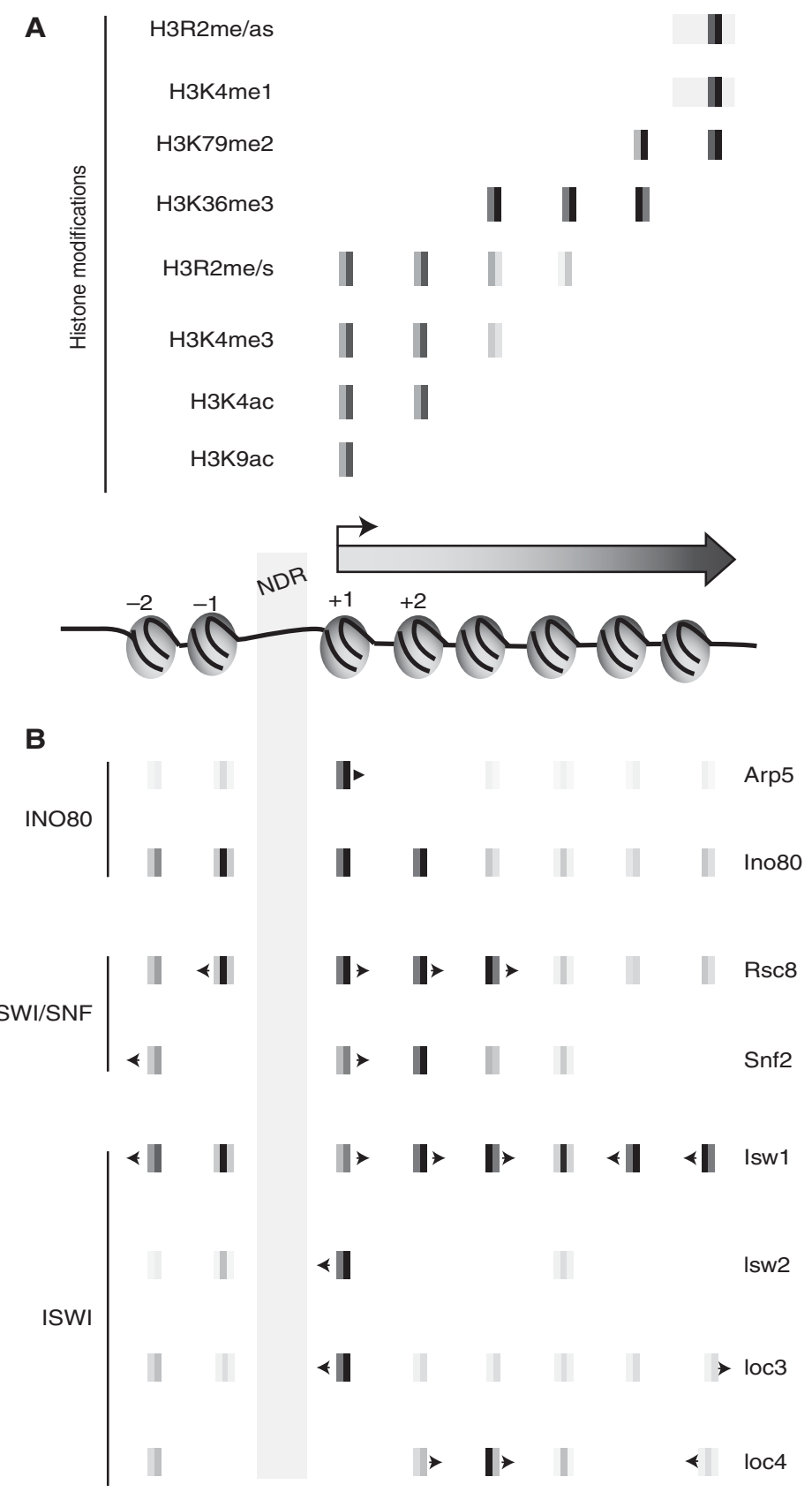

Figure 3. Predominant positions of histone modifications and chromatin remodelers relative to nucleosome depleted regions (NDRs). ( $A$ ) Histone modifications, and $(B)$ chromatin remodeling factors flanking NDRs are shown. Arrowheads point to the net directionality of nucleosome movement performed by the corresponding remodeler protein. Ino80 spreads across many positions, but the Arp 5 subunit is enriched at the +1 position. Rsc 8 and Snf2 are enriched predominantly at the first three genic nucleosomes, but Snf2 is largely depleted at the -1 position and enriched at -2 . Isw2 maps mainly to the +1 position and the regulatory subunit Ioc3 (ISW 1a) is particularly enriched at the +1 position, whereas Ioc4 (ISW1b) is enriched at positions $+2,+3$, and +4 . 
L. Székvölgyi et al.

Rec12 and DSB sites. (3) In budding yeast, deletion of the Sir2 histone deacetylase causes variable, but genome-wide changes in DSB formation, reducing or elevating DSB levels at $\sim 12 \%$ of hotspots (Mieczkowski et al. 2007). Sir 2 could actively repress DSBs within naturally cold regions (such as the rDNA cluster, telomeres, centromeres) to prevent nonallelic homologous recombination. Interestingly, even in the presence of active Sir2, the edges of the rDNA array remain exceptionally susceptible to meiotic DSBs (Vader et al. 2011). It has turned out that a secondary border-specific system, involving the meiotic ATPase Pch2 and Orc1, operates at heterochromatin-euchromatin junctions to shield the edges of the rDNA array. Pch2 is an evolutionarily conserved AAA-ATPase protein, which appears to influence the initiation of recombination and timely meiotic progression (Borner et al. 2008).

A number of studies indicate that histone $\mathrm{H} 3 \mathrm{~K} 4 \mathrm{me}$ is a fundamental mark of meiotic DSB formation, which is conserved from yeast to human: (1) deletion of the H3K4 methyltransferase Set1 or point mutation of the modifiable histone H3 lysine 4 residue severely reduce meiotic DSB levels at canonical hotspots in S. cerevisiae (Acquaviva et al. 2013; Sommermeyer et al. 2013); (2) absence of Set1 in the distantly related fission yeast partially reduces DSB formation at various loci, in which Set1 and $\mathrm{H} 3 \mathrm{~K} 9$ acetylation redundantly regulated meiotic DSB formation (Yamada et al. 2013); (3) deletion of RAD6, as well as the substitution of the ubiquitylation site on histone $\mathrm{H} 2 \mathrm{~B}$, both of which affect $\mathrm{H} 3 \mathrm{~K} 4$ methylation, decrease DSB frequencies at various hotspots (Yamashita et al. 2004); (4) H3K4me3 levels were significantly enriched at several yeast (Robine et al. 2007) and mouse (Smagulova et al. 2011) DSB hotspots, as well as at Arabidopsis thaliana CO hotspots (Choi et al. 2013); and (5) from mice to human, hotspot activity is largely dependent on Prdm9, the sequence-targeted meiosis-specific H3K4 methyltransferase (Grey et al. 2011).

Our latest work (Acquaviva et al. 2013) has revealed a causative and unexpected link between the presence of histone $\mathrm{H} 3$ lysine 4 methylation and DSB formation. A genetically engi- neered Set1 histone methyltransferase (Gal4BDSet1) targeted to recombination cold regions readily induces DSB formation at these sites (Fig. 4A). The DSB-inducing effect of Gal4BDSet1 depends on the presence of the modifiable lysine 4 residue (because DSBs at these sites were abolished in the H3K4R mutant), revealing a cause-effect relationship between the presence of histone $\mathrm{H} 3 \mathrm{~K} 4 \mathrm{me}$ and meiotic DSB formation. Unexpectedly, although Gal4BDSet1-induced DSBs were strongly dependent on Spp1, the PHD-finger subunit of COMPASS (Fig. 4A), the reverse was not true: tethering of Spp 1 to recombination cold spots (Gal4BDSpp1) strongly induced DSB formation, but these breaks were largely independent of Set1 and histone H3K4me (Fig. 4B). Moreover, the Gal4BD-Spp1-induced DSBs were maintained in both set $1 \Delta$ and H3K4R mutants, indicating that Spp1 on its own is able to initiate meiotic recombination when recruited to the chromosomes. The DSB-promoting effect of Spp 1 is mediated via its PHD finger domain, binding to H3K4 trimethylated nucleosomes, and by its physical interaction with the "core" DSB protein Mer2 (Acquaviva et al. 2013; Sommermeyer et al. 2013). Collectively, these findings suggest that Spp1 makes a contact bridge between DSB hotspots and the chromosomal axis via contacts with Mer2 and histone $\mathrm{H} 3 \mathrm{~K} 4 \mathrm{me} 3$, and contrast the situation in fission yeast, which uses a meiosis-specific bridge protein (liaisonin) to mediate axis-DSB hotspot interaction (Miyoshi et al. 2012).

It should also be noted that a subclass of budding yeast DSB cold spots, localized proximal to chromosomal axes, are associated with lower histone $\mathrm{H} 3 \mathrm{~K} 4 \mathrm{me} 3$. In budding yeast, binding of Rec8, the kleisin subunit of meiotic cohesin, along chromosome axes plays a critical role in determining the canonical distribution of meiotic DSB sites (Kugou et al. 2009). Regions spanning $\pm 0.8 \mathrm{kbp}$ around axial Rec8 binding sites show lower Spo11-oligo frequency (Ito et al. 2014). Moreover, Spo11 fused with the Gal4 DNA-binding domain (Gal4BD-Spo11) cannot form meiotic DSBs efficiently when targeted to sites adjacent to $\operatorname{Rec} 8$ binding sites. In addition, H3K4me3 levels are remarkably lower in Rec8 
Meiotic DSBs: Toward Chromatin Architecture

A
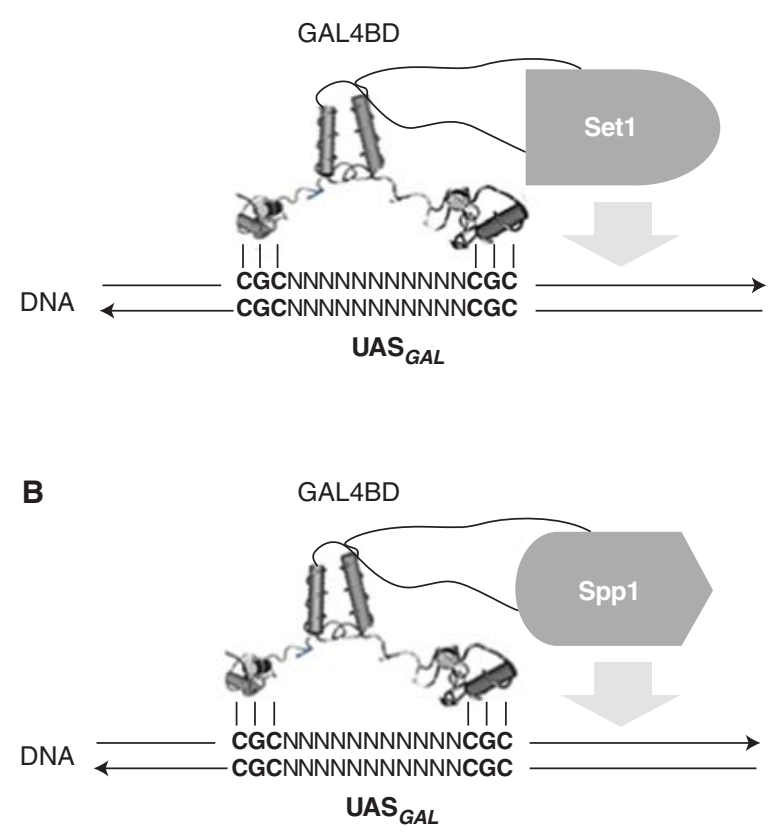

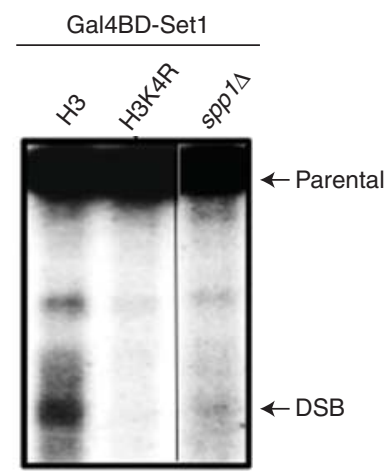

Gal4BD-Spp1

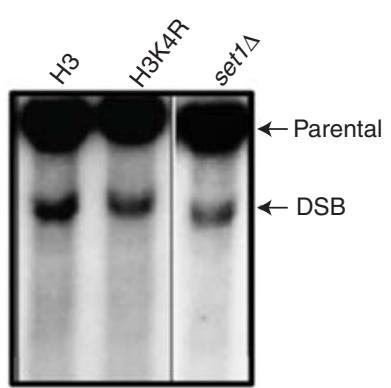

Figure 4. Modulating the double-strand break (DSB) pattern by targeting COMPASS proteins to ectopic chromosomal regions. (A) Gal4BD-Set1, and (B) Gal4BD-Spp1 fusion proteins induce meiotic DSB formation within recombinationally cold regions. Gal4BD-Set1-targeted DSBs depend on the presence of the modifiable histone H3 lysine 4 residue (H3K4R mutant), as well as the presence of Spp1 (spp1 $\Delta$ mutant), whereas Gal4BDSpp1-targeted DSBs are independent of the H3 lysine 4 residue and Set1 $(\operatorname{set} 1 \Delta$ mutant). UAS, upstream activating sequence.

binding sites. It is, thus, suggested that reduced histone H3K4me3 down-regulates Spo11 activity on sequences proximal to the axes. One possible mechanism is that the absence of $\mathrm{H} 3 \mathrm{~K} 4 \mathrm{me} 3$ around the axis hampers formation of tethered axis-loop complexes resulting in local inhibition of DSBs.

Collectively, these recent studies strongly implicate COMPASS, H3K4me3, and Mer2 in the determination of DSB sites. However, there are several key unknowns to understand the relationship among meiotic DSB sites, histone modifications, and higher-order genome architecture. For example, (1) existence of axis-loop contacts and their role in DSB formation have not been proven at the molecular levels ( physical evidence is missing); (2) it is not known which chromatin proteins and histone modifications, in particular, COMPASS, Mer2, and H3K4me3, make or participate in mediating these contacts (causality is missing); and (3) mechanisms for DSB site selection in the absence of H3K4 methylation and repression of Spo11 activity in Rec8 binding sites with lower H3K4me3 remain unknown. Even if not absolutely required, the broadly localized $\mathrm{H} 3 \mathrm{~K} 4 \mathrm{me} 3$ modification has the virtue of permitting the initiation of recombination at numerous places of the genome, a molecular strategy that provides flexibility and ensures a large diversity of recombinant haplotypes to be transmitted by the gametes.

\section{CHROMATIN REMODELERS AND HISTONE MODIFICATIONS}

Chromatin remodeling factors (Table 1) can significantly accelerate the dynamics of nucleo- 
L. Székvölgyi et al.

somes to allow for more rapid and localized access of Spo11 to meiotic DSB sites. For instance, the fission yeast SWI/SNF-type ATP-dependent remodeler SNF22 and CHD-1-type ATP-dependent remodeler Hrp3 activate the M26 recombination hotspot before DSB formation (Yamada et al. 2004). During DSB repair in mitotically cycling cells, chromatin remodelers exhaustively participate in disrupting and mobilizing nucleosomes (Mellor and Morillon 2004; Seeber et al. 2013). (1) Physical tethering of INO80 (LexA-Ino80) to lacO-tagged DSBs enhances the mobility of the breaks, causing increased gene conversion rates at ectopic donor sites (Neumann et al. 2012); also, INO80 is recruited to DSBs by carboxy-terminally phosphorylated $\gamma \mathrm{H} 2 \mathrm{AX}$, in which it evicts/remodels the H2A.Z variant nucleosomes (Htzl in yeast) to facilitate end resection. (2) Fun30 mediates the process of end resection after DSB induction (Chen et al. 2012). (3) Rad54 mediates strandexchange reactions during Holliday junction formation and resolution (Nimonkar et al. 2012). Whether the same remodeling factors function in meiotic recombination remains unclear.

A number observation points toward a functional link between chromatin remodelers and histone modifications (however, these relationships can be rather complex as the latter affects the sites of chromatin remodeling, and vice versa). (1) On meiotic DSB formation, there is the rapid appearance of open chromatin-showing increased DNaseI and MNase sensitivity at hotspots-promptly followed by $\gamma \mathrm{H} 2 \mathrm{AX}$ phosphorylation and histone $\mathrm{H} 4$ acetylation spreading over hundreds of kbps away from breaks (Ohta et al. 1994; Downs et al. 2004). (2) Histone H3K56 acetylation (H3K56ac) and SWR1 are mechanistically coupled as acetylated H3K56 modulates the specificity of SWR1 to remove the histone variant H2A.Z from gene regulatory regions (Watanabe et al. 2013). It is also known that A. thaliana meiotic DSB sites significantly overlap with H2A.Z nucleosomes and H3K4me3 (similarly to $S$ cerevisiae) and the SWRI-deposited H2A.Z nucleosomes promote meiotic DSB formation and repair (Choi et al. 2013). (3) Members of the SWI/SNF family have carboxy-terminal bromodomains, which interact with acetylated histones, to preferentially target the acetylated nucleosomes for eviction (Yodh 2013). (4) The CHD remodelers have two tandem chromodomains, recognizing methylated histone $\mathrm{H} 3$ tails.

Bai et al. 2011 has screened $\sim 6000$ S. cerevisiae nucleosome-depleted regions (NDRs) for consensus binding sites of known nucleosomedepleting factors (NDFs), including remodelers (e.g., Rsc3) and transcription factors (e.g., Abf1, Rap1, Reb1). A significant fraction of NDRs (30\%) contained at least one NDF binding site. Similar observations were published in S. pombe (De et al. 2012), which together suggest that different NDRs depend on the modular binding of NDFs (remodelers, transcription factors, and histone modifiers). As not all NDRs constitute a functional recombination hotspot (Pan et al. 2011), it is easy to envisage that only a combinatorial association of these factors makes an NDR competent for recruiting the Spo11 machinery to initiate homologous recombination.

Table 1. Chromatin remodeling factors

\begin{tabular}{clllc}
\hline & SWI/SNF & \multicolumn{1}{c}{ ISWI } & CHD & INO80/SWRI \\
\hline $\begin{array}{c}\text { Saccharomyces } \\
\text { cerevisiae }\end{array}$ & SWI/SNF & ISWI1a & CHD1 & INO80 \\
& RSC & ISWI1b & & SWRI \\
Homo sapiens & ISW2 & NuRD & INO80 \\
& SWI/SNF & ACF/WCFR & & SRCAP \\
& & CHRAC & & \\
& RSF & & \\
& WICH &
\end{tabular}

Yeast and human chromatin remodeling complexes classified by their ATPase subunits. CHD, chromo-helicase/ATPase DNA binding. 
In a systematic analysis, Yen et al. (2013) has revealed that remodelers bind to DNA in a nucleosome-position and orientation-specific manner. Nucleosomes are mobilized with a predefined net directionality relative to NDRs (toward or away from them), such that (1) remodelers bind predominantly to the +1 nucleosome, or (2) they are located at multiple positions along the ORF (Fig. 3B). For example, Ino80 spreads across many positions, but the Arp5 subunit of the same INO80 complex is enriched at the +1 position, moving this nucleosome $5^{\prime}$ to $3^{\prime}$. In line with the above, the RSC (remodels the structure of chromatin) remodeling complex plays a highly specific role in the precise positioning of nucleosomes over yeast promoter, a function that cannot be replaced by other closely related remodeling enzymes (Wippo et al. 2011). All of the above collectively suggest that \pm 1 nucleosome-flanking NDRs are differentially processed by remodelers such that the initial positioning of this particular nucleosome may automatically cause the positioning of adjacent nucleosomes. Therefore, NDRs, in which most meiotic DSBs fall in S. cerevisiae and Arabidopsis, might be the active organizing centers (not just simple bystanders) of DNA cleavage in meiosis.

\section{CONCLUDING REMARKS}

Numerous studies have suggested that posttranslational histone modifications do not represent a "code" (Sims and Reinberg 2008; Lee et al. 2010), but that the majority of these chemical tags mobilize or immobilize, rather than mark, the nucleosomes. Because of the stringent spatial order of histone modifications that flank meiotic DSB sites, many aspects of meiotic DSB control, including hotspot intensity, clustering/ interference, and compensation, might operate at the level of the well-positioned \pm 1 nucleosomes bordering DSB hotspots. Indeed, binding of Prdm9 to DSB sites actively reorganizes the flanking \pm 1 nucleosomes, creating a symmetrical pattern of NDRs centered over the 13-mer consensus binding motif of the PRDM9 zincfinger array (Baker et al. 2014). In this way, H3K4 methylated nucleosomes establish a per- missible chromatin structure for meiotic DSB formation, depending on the activity of PRDM9.

In conclusion, the \pm 1 nucleosome-flanking meiotic DSB hotspots seem to be critical for meiotic recombination initiation and repair. We propose that a combinatorial association of histone modifications and nucleosome remodelers positively (or negatively) regulates the turnover/mobility of the critical \pm 1 nucleosome. This, in turn, automatically positions the adjacent nucleosomes to establish a permissive (or restrictive) chromatin context for recombination. The resultant effect of these activities is expected to modulate the efficiency of Spo11-mediated DNA cleavage at meiotic recombination hotspots.

\section{ACKNOWLEDGMENTS}

Work in the A. Nicolas laboratory was supported by a grant from Meiogenix SA. L.S. was supported by the European Union (FP7/MCACIG), CRP-ICGEB (Trieste, Italy), and the Hungarian Scientific Research Fund (OTKA$\mathrm{PD})$, cofinanced by the European Social Fund in the framework of TÁMOP-4.2.4.A/2-11/12012-0001 National Excellence Program. K.O. was supported by a Grant-in-Aid for Scientific Research on Innovative Areas and Platform for Dynamic Approaches to Living System from The Ministry of Education, Culture, Sports, Science and Technology (MEXT) and the Japan Society for the Promotion of Science (JSPS).

\section{REFERENCES}

*Reference is also in this collection.

Acquaviva L, Székvölgyi L, Dichtl B, Dichtl BS, de La Roche Saint André C, Nicolas A, Geli V. 2013. The COMPASS subunit Sppl links histone methylation to initiation of meiotic recombination. Science 339: 215-218.

Arora C, Kee K, Maleki S, Keeney S. 2004. Antiviral protein Ski8 is a direct partner of Spol1 in meiotic DNA break formation, independent of its cytoplasmic role in RNA metabolism. Mol Cell 13: 549-559.

Auton A, Fledel-Alon A, Pfeifer S, Venn O, Segurel L, Street T, Leffler EM, Bowden R, Aneas I, Broxholme J, et al. 2012. A fine-scale chimpanzee genetic map from population sequencing. Science 336: 193-198.

Bai L, Ondracka A, Cross FR. 2011. Multiple sequence-specific factors generate the nucleosome-depleted region on CLN2 promoter. Mol Cell 42: 465-476. 
Baker CL, Walker M, Kajita S, Petkov PM, Paigen K. 2014 PRDM9 binding organizes hotspot nucleosomes and limits Holliday junction migration. Genome Res 24: $724-732$.

Baudat F, Nicolas A. 1997. Clustering of meiotic doublestrand breaks on yeast chromosome III. Proc Natl Acad Sci 94: 5213-5218.

Bergerat A, de Massy B, Gadelle D, Varoutas PC, Nicolas A, Forterre P. 1997. An atypical topoisomerase II from $\mathrm{Ar}$ chaea with implications for meiotic recombination. $\mathrm{Na}$ ture 386: 414-417.

Bishop DK. 1994. RecA homologs Dmcl and Rad51 interact to form multiple nuclear complexes prior to meiotic chromosome synapsis. Cell 79: 1081-1092.

Blitzblau HG, Hochwagen A. 2013. ATR/Mec1 prevents lethal meiotic recombination initiation on partially replicated chromosomes in budding yeast. eLife 2: e00844.

Borde V, Lin W, Novikov E, Petrini JH, Lichten M, Nicolas A. 2004. Association of Mre1lp with double-strand break sites during yeast meiosis. Mol Cell 13: 389-401.

Borde V, Robine N, Lin W, Bonfils S, Geli V, Nicolas A. 2009. Histone $\mathrm{H} 3$ lysine 4 trimethylation marks meiotic recombination initiation sites. EMBO J 28: 99-111.

Borner GV, Barot A, Kleckner N. 2008. Yeast Pch2 promotes domainal axis organization, timely recombination progression, and arrest of defective recombinosomes during meiosis. Proc Natl Acad Sci 105: 3327-3332.

Bowring FJ, Yeadon PJ, Stainer RG, Catcheside DE. 2006. Chromosome pairing and meiotic recombination in Neurospora crassa spo11 mutants. Curr Genet 50: 115123.

Brick K, Smagulova F, Khil P, Camerini-Otero RD, Petukhova GV. 2012. Genetic recombination is directed away from functional genomic elements in mice. Nature 485: 642-645.

Buhler C, Borde V, Lichten M. 2007. Mapping meiotic single-strand DNA reveals a new landscape of DNA doublestrand breaks in Saccharomyces cerevisiae. PLoS Biol 5: e324.

Campbell CD, Eichler EE. 2013. Properties and rates of germline mutations in humans. Trends Genet 29: 575584.

Chen X, Cui D, Papusha A, Zhang X, Chu CD, Tang J, Chen K, Pan X, Ira G. 2012. The Fun30 nucleosome remodeller promotes resection of DNA double-strand break ends. Nature 489: 576-580.

Choi K, Zhao X, Kelly KA, Venn O, Higgins JD, Yelina NE, Hardcastle TJ, Ziolkowski PA, Copenhaver GP, Franklin FC, et al. 2013. Arabidopsis meiotic crossover hot spots overlap with H2A.Z nucleosomes at gene promoters. Nat Genet 45: 1327-1336.

Cole F, Keeney S, Jasin M. 2010. Comprehensive, fine-scale dissection of homologous recombination outcomes at a hot spot in mouse meiosis. Mol Cell 39: 700-710.

Cromie GA, Hyppa RW, Cam HP, Farah JA, Grewal SI, Smith GR. 2007. A discrete class of intergenic DNA dictates meiotic DNA break hotspots in fission yeast. PLoS Genet 3: e141.

de Castro E, Soriano I, Marin L, Serrano R, Quintales L, Antequera F. 2012. Nucleosomal organization of replica- tion origins and meiotic recombination hotspots in fission yeast. EMBO J 31: 124-137.

Downs JA, Allard S, Jobin-Robitaille O, Javaheri A, Auger A, Bouchard N, Kron SJ, Jackson SP, Cote J. 2004. Binding of chromatin-modifying activities to phosphorylated histone H2A at DNA damage sites. Mol Cell 16: 979-990.

Drouaud J, Khademian H, Giraut L, Zanni V, Bellalou S, Henderson IR, Falque M, Mezard C. 2013. Contrasted patterns of crossover and non-crossover at Arabidopsis thaliana meiotic recombination hotspots. PLoS Genet 9: $\mathrm{e} 1003922$.

Fan QQ, Xu F, White MA, Petes TD. 1997. Competition between adjacent meiotic recombination hotspots in the yeast Saccharomyces cerevisiae. Genetics 145: 661670.

Farah JA, Cromie GA, Smith GR. 2009. Ctp1 and Exonuclease 1, alternative nucleases regulated by the MRN complex, are required for efficient meiotic recombination. Proc Natl Acad Sci 106: 9356-9361.

Fowler KR, Sasaki M, Milman N, Keeney S, Smith GR. 2014. Evolutionarily diverse determinants of meiotic DNA break and recombination landscapes across the genome. Genome Res 24: 1650-1664.

Gerton JL, DeRisi J, Shroff R, Lichten M, Brown PO, Petes TD. 2000. Global mapping of meiotic recombination hotspots and coldspots in the yeast Saccharomyces cerevisiae. Proc Natl Acad Sci 97: 11383-11390.

Gray S, Allison RM, Garcia V, Goldman AS, Neale MJ. 2013. Positive regulation of meiotic DNA double-strand break formation by activation of the DNA damage checkpoint kinase Mecl(ATR). Open Biol 3: 130019.

Grey C, Barthes P, Chauveau-Le FG, Langa F, Baudat F, de Massy B. 2011. Mouse PRDM9 DNA-binding specificity determines sites of histone $\mathrm{H} 3$ lysine 4 trimethylation for initiation of meiotic recombination. PLoS Biol 9: e1001176.

Hayashi K, Yoshida K, Matsui Y. 2005. A histone H3 methyltransferase controls epigenetic events required for meiotic prophase. Nature 438: 374-378.

Hodgson A, Terentyev Y, Johnson RA, Bishop-Bailey A, Angevin T, Croucher A, Goldman AS. 2011. Mre11 and Exo1 contribute to the initiation and processivity of resection at meiotic double-strand breaks made independently of Spo11. DNA Repair (Amst) 10: 138-148.

Ito M, Kugou K, Fawcett JA, Mura S, Ikeda S, Innan H, Ohta K. 2014. Meiotic recombination cold spots in chromosomal cohesion sites. Genes Cells 19: 359-373.

Kolodkin AL, Klar AJ, Stahl FW. 1986. Double-strand breaks can initiate meiotic recombination in S. cerevisiae. Cell 46: $733-740$.

Kong A, Thorleifsson G, Frigge ML, Masson G, Gudbjartsson DF, Villemoes R, Magnusdottir E, Olafsdottir SB, Thorsteinsdottir U, Stefansson K. 2014. Common and low-frequency variants associated with genome-wide recombination rate. Nat Genet 46: 11-16.

Kugou K, Fukuda T, Yamada S, Ito M, Sasanuma H, Mori S, Katou Y, Itoh T, Matsumoto K, Shibata T, et al. 2009. Rec8 guides canonical Spo11 distribution along yeast meiotic chromosomes. Mol Biol Cell 20: 3064-3076. 
* Lam I, Keeney S. 2015. Mechanism and regulation of meiotic recombination initiation. Cold Spring Harb Perspect Biol 7: a016634.

Lao JP, Cloud V, Huang CC, Grubb J, Thacker D, Lee CY, Dresser ME, Hunter N, Bishop DK. 2013. Meiotic crossover control by concerted action of Rad51-Dmcl in homolog template bias and robust homeostatic regulation. PLoS Genet 9: e1003978.

Lee JS, Smith E, Shilatifard A. 2010. The language of histone crosstalk. Cell 142: 682-685.

Malkova A, Klein F, Leung WY, Haber JE. 2000. HO endonuclease-induced recombination in yeast meiosis resembles Spo11-induced events. Proc Natl Acad Sci 97: 14500-14505.

Mancera E, Bourgon R, Brozzi A, Huber W, Steinmetz LM. 2008. High-resolution mapping of meiotic crossovers and non-crossovers in yeast. Nature 454: 479-485.

Mellor J, Morillon A. 2004. ISWI complexes in Saccharomyces cerevisiae. Biochim Biophys Acta 1677: 100-112.

Mieczkowski PA, Dominska M, Buck MJ, Lieb JD, Petes TD. 2007. Loss of a histone deacetylase dramatically alters the genomic distribution of Spol1p-catalyzed DNA breaks in Saccharomyces cerevisiae. Proc Natl Acad Sci 104: 3955-3960.

Miyoshi T, Ito M, Kugou K, Yamada S, Furuichi M, Oda A, Yamada T, Hirota K, Masai H, Ohta K. 2012. A central coupler for recombination initiation linking chromosome architecture to S phase checkpoint. Mol Cell 47: $722-733$.

Myers S, Bowden R, Tumian A, Bontrop RE, Freeman C, MacFie TS, McVean G, Donnelly P. 2010. Drive against hotspot motifs in primates implicates the PRDM9 gene in meiotic recombination. Science 327: 876-879.

Neale MJ, Pan J, Keeney S. 2005. Endonucleolytic processing of covalent protein-linked DNA double-strand breaks. Nature 436: 1053-1057.

Neumann FR, Dion V, Gehlen LR, Tsai-Pflugfelder M, Schmid R, Taddei A, Gasser SM. 2012. Targeted INO80 enhances subnuclear chromatin movement and ectopic homologous recombination. Genes Dev 26: 369-383.

Nimonkar AV, Dombrowski CC, Siino JS, Stasiak AZ, Stasiak A, Kowalczykowski SC. 2012. Saccharomyces cerevisiae Dmc1 and Rad51 proteins preferentially function with Tid1 and Rad54 proteins, respectively, to promote DNA strand invasion during genetic recombination. J Biol Chem 287: 28727-28737.

Ohta K, Shibata T, Nicolas A. 1994. Changes in chromatin structure at recombination initiation sites during yeast meiosis. EMBO J 13: 5754-5763.

Pan J, Sasaki M, Kniewel R, Murakami H, Blitzblau HG, Tischfield SE, Zhu X, Neale MJ, Jasin M, Socci ND, et al. 2011. A hierarchical combination of factors shapes the genome-wide topography of yeast meiotic recombination initiation. Cell 144: 719-731.

Panizza S, Mendoza MA, Berlinger M, Huang L, Nicolas A, Shirahige K, Klein F. 2011. Spol1-accessory proteins link double-strand break sites to the chromosome axis in early meiotic recombination. Cell 146: 372-383.

Pecina A, Smith KN, Mezard C, Murakami H, Ohta K, Nicolas A. 2002. Targeted stimulation of meiotic recombination. Cell 111: 173-184.
Qiao H, Prasada Rao HB, Yang Y, Fong JH, Cloutier JM, Deacon DC, Nagel KE, Swartz RK, Strong E, et al. 2014. Antagonistic roles of ubiquitin ligase HEI10 and SUMO ligase RNF212 regulate meiotic recombination. Nat Genet 46: 194-199.

Reynolds A, Qiao H, Yang Y, Chen JK, Jackson N, Biswas K, Holloway JK, Baudat F, de Massy B, Wang J, et al. 2013. RNF212 is a dosage-sensitive regulator of crossing-over during mammalian meiosis. Nat Genet 45: 269-278.

Robert V, Bessereau JL. 2007. Targeted engineering of the Caenorhabditis elegans genome following Mos1-triggered chromosomal breaks. EMBO J 26: 170-183.

Robine N, Uematsu N, Amiot F, Gidrol X, Barillot E, Nicolas A, Borde V. 2007. Genome-wide redistribution of meiotic double-strand breaks in Saccharomyces cerevisiae. Mol Cell Biol 27: 1868-1880

Rocco V, de Massy B, Nicolas A. 1992. The Saccharomyces cerevisiae ARG4 initiator of meiotic gene conversion and its associated double-strand DNA breaks can be inhibited by transcriptional interference. Proc Natl Acad Sci 89: $12068-12072$.

Rufiange A, Jacques P.E., Bhat W, Robert F, Nourani A. 2007. Genome-wide replication-independent histone H3 exchange occurs predominantly at promoters and implicates H3 K56 acetylation and Asf1. Mol Cell 27: 393-405.

Schwartzentruber J, Korshunov A, Liu XY, Jones DT, Pfaff E, Jacob K, Sturm D, Fontebasso AM, Quang DA, Tonjes M, et al. 2012. Driver mutations in histone H3.3 and chromatin remodelling genes in paediatric glioblastoma. $\mathrm{Na}$ ture 482: 226-231.

Seeber A, Hauer M, Gasser SM. 2013. Nucleosome remodelers in double-strand break repair. Curr Opin Genet Dev 23: $174-184$.

Serrentino ME, Chaplais E, Sommermeyer V, Borde V. 2013. Differential association of the conserved SUMO ligase Zip3 with meiotic double-strand break sites reveals regional variations in the outcome of meiotic recombination. PLoS Genet 9: e1003416.

Sims RJ III, Reinberg D. 2008. Is there a code embedded in proteins that is based on post-translational modifications? Nat Rev Mol Cell Biol 9: 815-820.

Sleutels F, Soochit W, Bartkuhn M, Heath H, Dienstbach S, Bergmaier P, Franke V, Rosa-Garrido M, van de Nobelen $\mathrm{S}$, Caesar L, et al. 2012. The male germ cell gene regulator CTCFL is functionally different from CTCF and binds CTCF-like consensus sites in a nucleosome composition-dependent manner. Epigenetics Chromatin 5: 8.

Smagulova F, Gregoretti IV, Brick K, Khil P, Camerini-Otero RD, Petukhova GV. 2011. Genome-wide analysis reveals novel molecular features of mouse recombination hotspots. Nature 472: $375-378$.

Sommermeyer V, Beneut C, Chaplais E, Serrentino ME, Borde V. 2013. Spp1, a member of the Setl Complex, promotes meiotic DSB formation in promoters by tethering histone $\mathrm{H} 3 \mathrm{~K} 4$ methylation sites to chromosome axes. Mol Cell 49: 43-54.

Székvölgyi L, Nicolas A. 2010. From meiosis to postmeiotic events: Homologous recombination is obligatory but flexible. FEBS J 277: 571-589.

Vader G, Blitzblau HG, Tame MA, Falk JE, Curtin L, Hochwagen A. 2011. Protection of repetitive DNA borders 


\section{Székvölgyi et al.}

from self-induced meiotic instability. Nature 477: 115119.

Wagner CR, Kuervers L, Baillie DL, Yanowitz JL. 2010. xnd-1 regulates the global recombination landscape in Caenorhabditis elegans. Nature 467: 839-843.

Watanabe Y. 2012. Geometry and force behind kinetochore orientation: Lessons from meiosis. Nat Rev Mol Cell Biol 13: $370-382$.

Watanabe S, Radman-Livaja M, Rando OJ, Peterson CL. 2013. A histone acetylation switch regulates H2A.Z deposition by the SWR-C remodeling enzyme. Science 340: 195-199.

Wippo CJ, Israel L, Watanabe S, Hochheimer A, Peterson CL, Korber P. 2011. The RSC chromatin remodelling enzyme has a unique role in directing the accurate positioning of nucleosomes. EMBO J 30: 1277-1288.

Xu L, Kleckner N. 1995. Sequence non-specific doublestrand breaks and interhomolog interactions prior to double-strand break formation at a meiotic recombination hot spot in yeast. EMBO J 14: 5115-5128.

Yamada T, Mizuno K, Hirota K, Kon N, Wahls WP, Hartsuiker E, Murofushi H, Shibata T, Ohta K. 2004. Roles of histone acetylation and chromatin remodeling factor in a meiotic recombination hotspot. EMBO J 23: 1792-1803.
Yamada S, Ohta K, Yamada T. 2013. Acetylated histone $\mathrm{H} 3 \mathrm{~K} 9$ is associated with meiotic recombination hotspots, and plays a role in recombination redundantly with other factors including the $\mathrm{H} 3 \mathrm{~K} 4$ methylase Set1 in fission yeast. Nucleic Acids Res 41: 3504-3517.

Yamashita K, Shinohara M, Shinohara A. 2004. Rad6-Bre1mediated histone $\mathrm{H} 2 \mathrm{~B}$ ubiquitylation modulates the formation of double-strand breaks during meiosis. Proc Nat Acad Sci 101: 11380-11385.

Yen K, Vinayachandran V, Pugh BF. 2013. SWR-C and INO80 chromatin remodelers recognize nucleosomefree regions near +1 nucleosomes. Cell 154: 1246-1256.

Yodh J. 2013. ATP-dependent chromatin remodeling. Adv Exp Med Biol 767: 263-295.

Zhang L, Kim KP, Kleckner NE, Storlazzi A. 2011a. Meiotic double-strand breaks occur once per pair of ( sister) chromatids and, via Mec1/ATR and Tell/ATM, once per quartet of chromatids. Proc Natl Acad Sci 108: 2003620041.

Zhang L, Ma H, Pugh BF. 2011b. Stable and dynamic nucleosome states during a meiotic developmental process. Genome Res 21: 875-884.

* Zickler D, Kleckner N. 2015. Recombinatin, pairing, and synapsis of homologs during meiosis. Cold Spring Harb Perspect Biol doi: 10.1101/cshperspect.a016626. 


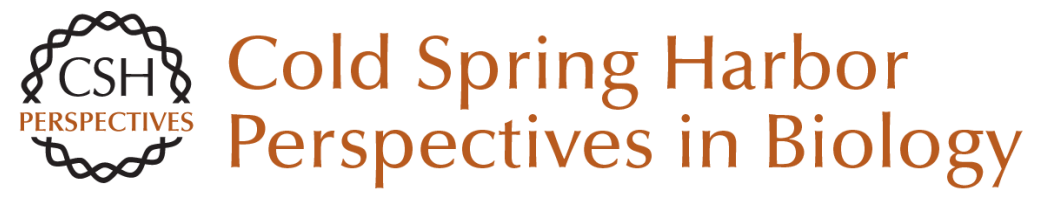

\section{Initiation of Meiotic Homologous Recombination: Flexibility, Impact of Histone Modifications, and Chromatin Remodeling}

Lóránt Székvölgyi, Kunihiro Ohta and Alain Nicolas

Cold Spring Harb Perspect Biol 2015; doi: 10.1101/cshperspect.a016527

Subject Collection DNA Recombination

Meiotic Recombination: The Essence of Heredity Neil Hunter

Regulation of Recombination and Genomic Maintenance Wolf-Dietrich Heyer

Initiation of Meiotic Homologous Recombination: Flexibility, Impact of Histone Modifications, and Chromatin Remodeling Lóránt Székvölgyi, Kunihiro Ohta and Alain Nicolas

Mechanism and Regulation of Meiotic

Recombination Initiation Isabel Lam and Scott Keeney

Homologous Recombination and Human Health: The Roles of BRCA1, BRCA2, and Associated Proteins

Rohit Prakash, Yu Zhang, Weiran Feng, et al.

Cell Biology of Mitotic Recombination

Michael Lisby and Rodney Rothstein

DNA-Pairing and Annealing Processes in Homologous Recombination and Homology-Directed Repair Scott W. Morrical
An Overview of the Molecular Mechanisms of

Recombinational DNA Repair

Stephen C. Kowalczykowski

Recombination, Pairing, and Synapsis of Homologs during Meiosis

Denise Zickler and Nancy Kleckner

DNA Strand Exchange and RecA Homologs in

Meiosis

M. Scott Brown and Douglas K. Bishop

Meiosis and Maternal Aging: Insights from

Aneuploid Oocytes and Trisomy Births Mary Herbert, Dimitrios Kalleas, Daniel Cooney, et al.

Mismatch Repair during Homologous and

Homeologous Recombination Maria Spies and Richard Fishel

Mechanisms of Gene Duplication and

Amplification

Andrew B. Reams and John R. Roth

The Role of Double-Strand Break Repair Pathways at Functional and Dysfunctional Telomeres Ylli Doksani and Titia de Lange

For additional articles in this collection, see http://cshperspectives.cshlp.org/cgi/collection/

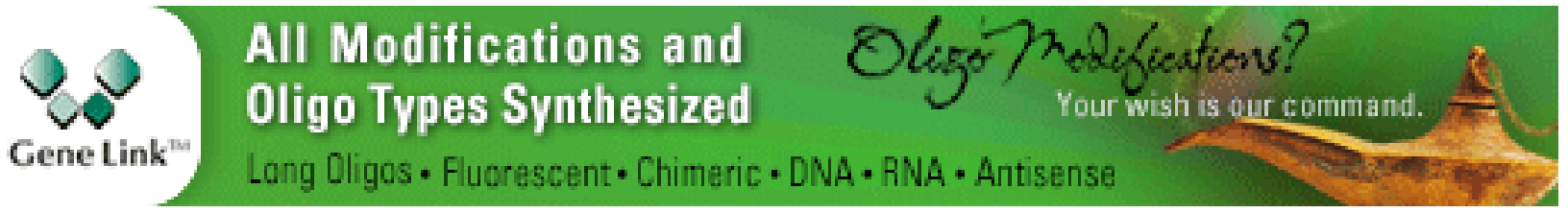




\section{Mediators of Homologous DNA Pairing}

Alex Zelensky, Roland Kanaar and Claire Wyman
Regulation of DNA Pairing in Homologous

Recombination

James M. Daley, William A. Gaines, YoungHo Kwon, et al.

For additional articles in this collection, see http://cshperspectives.cshlp.org/cgi/collection/

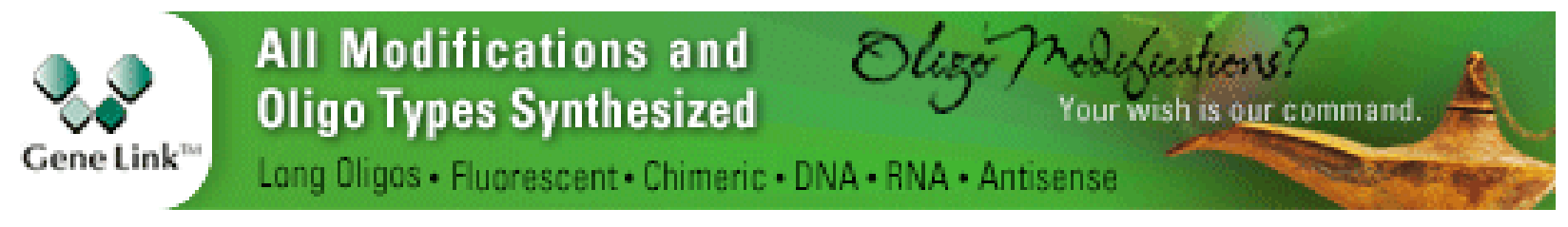

Copyright @ 2015 Cold Spring Harbor Laboratory Press; all rights reserved 